\title{
Toxicity of colloidal silica nanoparticles administered orally for 90 days in rats
}

\author{
This article was published in the following Dove Press journal: \\ International Journal of Nanomedicine \\ 15 December 2014 \\ Number of times this article has been viewed
}

\section{Yu-Ri Kim ${ }^{1, *}$ \\ Seung-Young Lee Le* $^{3, *}$ \\ Eun Jeong Lee' \\ Sung Ha Park ${ }^{4}$ \\ Nak-won Seong ${ }^{3}$ \\ Heung-Sik Seo ${ }^{3}$ \\ Sung-Sup $\mathrm{Shin}^{3}$ \\ Seon-Ju Kim ${ }^{3}$ \\ Eun-Ho Meang ${ }^{3}$ \\ Myeong-Kyu Park \\ Min-Seok Kim ${ }^{3}$ \\ Cheol-Su Kim ${ }^{5}$ \\ Soo-Ki Kim ${ }^{5}$ \\ Sang Wook Son ${ }^{2}$ \\ Young Rok Seo ${ }^{6}$ \\ Boo Hyon Kang ${ }^{7}$ \\ Beom Seok Han ${ }^{8}$ \\ Seong Soo A An ${ }^{9}$ \\ Beom-Jun Lee ${ }^{10}$ \\ Meyoung-Kon Kim'}

'Department of Biochemistry and Molecular Biology, ${ }^{2}$ Department of Dermatology, Korea University Medical School and College,

${ }^{3}$ General Toxicology Team, Korea Testing

and Research Institute, Seoul, Republic

of Korea; ${ }^{4}$ Department of Biochemistry,

University of Bath, Bath, UK; ${ }^{5}$ Department

of Microbiology, Wonju College of Medicine,

Yonsei University, Gangwon, ${ }^{6}$ Department

of Life Science, Institute of Environmental

Medicine for Green Chemistry, Dongguk

University, Seoul, ${ }^{7}$ Nonclinical Research

Institute, Chemon Inc, Gyeonggi,

${ }^{8}$ Toxicological Research Center, Hoseo

University, Chungnam, ${ }^{9}$ Department of

Bionanotechnology, Gachon University,

Gyeonggi, ${ }^{10} \mathrm{College}$ of Veterinary Medicine,

Chungbuk National University, Chungbuk,

Republic of Korea

*These authors contributed equally to this work

Correspondence: Beom-Jun Lee

College of Veterinary Medicine, Chungbuk

National University, 52 Naesudong-Ro

Seowon-gu, Cheongju-si, Chungbuk,

Republic of Korea

$\mathrm{Tel}+82432613357$

Fax +82 432713246

Email beomjun@cbu.ac.kr

Meyoung-Kon Kim

Department of Biochemistry and Molecular Biology, Korea University Medical School and College, Anam-Dong $5 \mathrm{Ga}$, Seounbuk-Gu,

Seoul I35-70I, Republic of Korea

$\mathrm{Tel}+82222866184$

Fax +82 29230480

Email jerrykim@korea.ac.kr
Abstract: This study was undertaken to investigate the potential toxicity and establish the no observed adverse effect level (NOAEL) and target organ(s) of negatively charged colloidal silica particles of different sizes, ie, $\mathrm{SiO}_{2}{ }^{\mathrm{EN} 20(-)}(20 \mathrm{~nm})$ or $\mathrm{SiO}_{2}{ }^{\mathrm{EN} 100(-)}(100 \mathrm{~nm})$, administered by gavage in Sprague-Dawley rats. After verification of the physicochemical properties of the $\mathrm{SiO}_{2}$ particles to be tested, a preliminary dose range-finding study and 90-day repeated dose study were conducted according to the Organisation for Economic Cooperation and Development test guideline. Based on the results of the 14-day dose range-finding study, a high dose was determined to be $2,000 \mathrm{mg} / \mathrm{kg}$, and middle and low doses were set at 1,000 and $500 \mathrm{mg} / \mathrm{kg}$, respectively. In the 90-day toxicity study, there were no animal deaths in relation to administration of $\mathrm{SiO}_{2}$ particles of either size. In addition, no treatment-related clinical changes or histopathological findings were observed in any of the experimental groups. Moreover, no difference in toxic effects from chronic exposure to $\mathrm{SiO}_{2}{ }^{\mathrm{EN} 20(-)}(20 \mathrm{~nm})$ or $\mathrm{SiO}_{2}{ }^{\mathrm{EN} 100(-)}(100 \mathrm{~nm})$ was observed. The results of this study indicate that the NOAEL for $\mathrm{SiO}_{2}{ }^{\mathrm{EN} 20(-)}$ and $\mathrm{SiO}_{2}{ }^{\mathrm{EN} 100(-)}$ would most likely be $2,000 \mathrm{mg} / \mathrm{kg}$, and no target organ was identified in rats of either sex.

Keywords: silica nanoparticles, particle size, 90-day oral dose toxicity, no observed adverse effect level

\section{Introduction}

Nanomaterials are commonly defined as materials designed and produced to have structural features with at least one dimension in the range of 1-100 nm. Nanoparticles (NPs) are now used commercially in health and fitness products, such as cosmetics, clothing, personal care items, sporting goods, and sunscreens. Moreover, NPs are expected to find applications in the medical field for diagnosis, imaging, and drug delivery. Silica $\left(\mathrm{SiO}_{2}\right)$ NPs, a typical nanomaterial, are currently being used in chemical-mechanical polishing, varnishes, printer toners,

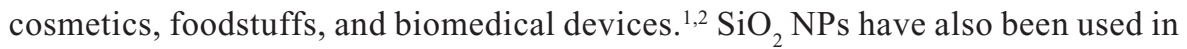
drug delivery matrices, in imaging devices, and as chemical sensors and catalysts because they are capable of various types of surface modifications, including chemical bonding between biomolecules and their own particle surfaces. ${ }^{1,3}$ Despite this wide range of applications, understanding of the potential toxic effects of $\mathrm{SiO}_{2}$ NPs is very limited.

The physicochemical properties of NPs, including their particle size, surface area, and shape, are considered to be critical factors in the assessment of their nanotoxicity. ${ }^{4,5}$ In particular, bulk-sized particles were known to retain their properties consistently, regardless of their particle size. However, nanosized particles have been shown to acquire new properties as their particle size decreases. Therefore, it would be necessary to investigate the toxic effects of NPs because they would behave differently 
according to their size. For example, Nabeshi et al showed that the bioproperties of nanosized $\mathrm{SiO}_{2}$ were different from those of bulk-sized $300 \mathrm{~nm}$ and $1,000 \mathrm{~nm} \mathrm{SiO}_{2}$ particles in vivo and in vitro. ${ }^{6}$ Further, when $\mathrm{SiO}_{2}$ NPs of various sizes $(30,70$, and $100 \mathrm{~nm})$ were administered intranasally to mice for 7 days, NPs $30 \mathrm{~nm}$ and $70 \mathrm{~nm}$ in size resulted in abnormal activation of the coagulation system. ${ }^{7}$ Other studies have reported that $\mathrm{SiO}_{2} \mathrm{NPs}$ also have cytotoxic effects by inducing reactive oxygen species in a particle size-dependent manner in in vitro systems. ${ }^{8,9}$ Therefore, we selected $20 \mathrm{~nm}$ and $100 \mathrm{~nm}$ sized particles of comparable diameters for analysis, where $100 \mathrm{~nm}$ was deemed to be at the high end of what can be considered "nanoparticulate".

Moreover, because of their small size, NPs can be exposed and internalized into biological systems through different routes, including oral administration, inhalation, dermal penetration, and intravenous injection. ${ }^{10} \mathrm{~A}$ number of in vivo studies have investigated the toxicity of $\mathrm{SiO}_{2} \mathrm{NPs}$ according to route of exposure. For instance, it was shown that intratracheal instillation of $\mathrm{SiO}_{2} \mathrm{NPs}$ caused moderate to severe pulmonary inflammation and tissue injury in mice. ${ }^{11}$ In contrast, Sayes et al reported that inhalation of aerosolized $\mathrm{SiO}_{2} \mathrm{NPs}$ in rats did not provoke a pulmonary inflammatory response, based on lung histopathology. ${ }^{12}$ On the other hand, intravenously administered $\mathrm{SiO}_{2}$ NPs caused liver damage in mice. ${ }^{13}$ Intraperitoneal injection of $\mathrm{SiO}_{2} \mathrm{NPs}$ in mice was also shown to induce a cytokine-mediated inflammatory response. ${ }^{14}$ Likewise, the majority of studies of the toxicity of $\mathrm{SiO}_{2}$ NPs in animal models were performed by inhalation and intraperitoneal or intravenous injection. Because $\mathrm{SiO}_{2}$ NPs could be used as a drug delivery carrier, agent of capsulated drug, oral administration would be the most likely route of exposure to $\mathrm{SiO}_{2} \mathrm{NPs}$, so the possibility of toxic effects through this pathway should not be ignored. Recently, Fu et al reported the toxicity of mesoporous $\mathrm{SiO}_{2}$ NPs administered orally in mice. ${ }^{15}$ Shortterm exposure studies are limited in their ability to evaluate nanotoxicity, and to date there has been no report of a repeated-dose oral toxicity study of $\mathrm{SiO}_{2} \mathrm{NPs}$ following Organisation for Economic Cooperation and Development (OECD) test guideline 408. ${ }^{16}$

In the present study, the possible toxic effects of 90 days of repeated oral administration of colloidal $\mathrm{SiO}_{2} \mathrm{NPs}$ of different sizes, ie, $20 \mathrm{~nm}$ and $100 \mathrm{~nm}$, were evaluated in Sprague-Dawley rats. Their no observed adverse effect level (NOAEL) and potential target organs were also investigated.

\section{Materials and methods Preparation of NPs}

Colloidal $\mathrm{SiO}_{2}$ NPs $20 \mathrm{~nm}$ and $100 \mathrm{~nm}$ diameter were purchased from E\&B Nanotech Co Ltd (Gyeonggi-do, Republic of Korea). The test particles were diluted in distilled water, and each of the tested doses (high, middle, and low) were formulated by dilution of the highest dose with distilled water. Before starting this study, the physicochemical properties of the two study particles were confirmed, including their primary particle size, morphology, hydrodynamic size, and zeta potential. ${ }^{17}$ As previously reported, ${ }^{17}$ the hydrodynamic sizes of $20 \mathrm{~nm}$ and $100 \mathrm{~nm} \mathrm{SiO}{ }_{2}$ NPs were 21.0 $\pm 0.1 \mathrm{~nm}$ and $91.6 \pm 0.5 \mathrm{~nm}$, respectively, and their zeta potentials were determined to be $-38.3 \pm 1.2$ and $-45.2 \pm 0.1 \mathrm{mV}$. Working samples of each dose formulation were prepared daily during the study. The formulated test particles were homogenized by vortexing just prior to administration.

\section{Experimental animals and animal husbandry}

Six-week-old Crl:CD(SD) specific pathogen-free rats were obtained from Orient Bio (Gyeonggi-do, Republic of Korea). Twenty-five animals of each sex were used in the dose range-finding study and 50 animals of each sex were used in the 90-day repeated oral toxicity study. Two animals per cage were housed in stainless steel wire cages $(270 \mathrm{~mm}$ width $\times 500 \mathrm{~mm}$ depth $\times 200 \mathrm{~mm}$ height) in a dedicated animal room maintained at a temperature of $21.5^{\circ} \mathrm{C}-23.3^{\circ} \mathrm{C}$ and a relative humidity of $42.0 \%-51.4 \%$, with light hours from 8 am to 8 pm (150-300 Lux) and a room ventilation frequency of 10-15 cycles per hour. Rodent feed and water were sterilized with 2.0 Mrad radiation and ultraviolet radiation, respectively, and both were available ad libitum. All animals were acclimated and quarantined for 8 days in a dedicated animal room. The study was conducted in compliance with the standards of Good Laboratory Practice, and performed in accordance with the regulations for the care and use of laboratory animals in the Health Care Research Laboratory of the Korea Testing and Research Institute (Institutional Animal Care and Use Committee, 2010) based on the Animal Protection Act No 10995 (2011, complete revision).

\section{Fourteen-day dose range-finding study}

After acclimatization and quarantine, the 25 healthy male and 25 healthy female rats selected for this study were randomly distributed into groups with approximately equal initial mean body weights. Based on the results of a preliminary acute oral pharmacokinetic absorption study (data not shown), in which 
no significant effect was observed in the $2,000 \mathrm{mg} / \mathrm{kg}$ group, the high dose for the 14-day study was set at $2,000 \mathrm{mg} / \mathrm{kg}$, with the middle and low doses set at 1,000 and $500 \mathrm{mg} / \mathrm{kg}$, respectively. Distilled water was administered to the negative control group. All experimental groups consisted of five rats of each sex. Body weight ranges at the time of initial dosing were 189.9-205.6 $\mathrm{g}$ for males and 154.5-166.6 $\mathrm{g}$ for females. The test formulation was administered by oral gavage between 9 am and noon, and the dose volume was $10 \mathrm{~mL} / \mathrm{kg}$ for all groups. Clinical signs and body weight were monitored throughout the 14-day study period, and gross findings were observed on the scheduled necropsy day.

\section{Ninety-day repeated oral administration toxicity study}

After acclimatization and quarantine, 50 healthy male and 50 healthy female animals selected for this study were distributed randomly in groups, with approximately equal initial mean body weights. No significant effects were observed at doses of 1,000 and $2,000 \mathrm{mg} / \mathrm{kg}$ in the 14-day repeated dose study (data not shown), so the high dose for this study was set at $2,000 \mathrm{mg} / \mathrm{kg}$, with the middle and low doses set at 1,000 and $500 \mathrm{mg} / \mathrm{kg}$, respectively. Distilled water was administered to the control group. Recovery was observed during a 2-week period after the end of treatment in the $2,000 \mathrm{mg} / \mathrm{kg}$ and negative control groups. The negative control and high-dose groups consisted of 15 rats of each sex, and the low-dose and middle-dose groups consisted of 10 rats of each sex. Body weight ranges at the time of dosing were 187.9-205.3 $\mathrm{g}$ for males and 143.3-167.1 $\mathrm{g}$ for females. The test formulation was administered into the stomach by oral gavage. After measuring body weight just prior to administration and once per week thereafter, the administration volume was calculated to be $10 \mathrm{~mL} / \mathrm{kg}$. The test formulation was administered once daily for 90 days. Assessment of treatment effects included clinical observation, body weight, feed and water consumption, urinalysis, ophthalmological testing, necropsy, organ weight, hematological and biochemical analysis, and histopathological observation.

\section{Observation and examination}

\section{Clinical signs}

During the study, all animals were observed once daily after treatment for well-being, death, and any clinical signs of toxicity.

\section{Feed and water consumption}

Feed and water consumption was recorded daily after the start of treatment. Consumption was calculated from the differences between the supplied amounts and the remaining amounts measured the next day.

\section{Urinalysis}

Urinalysis was performed for five animals per group of each sex during the last week of treatment using Multistix ${ }^{\circledR} 10 \mathrm{SG}$ strips (Siemens AG, München, Germany) and a Clinitek 500 urine analyzer (Siemens AG). Specific gravity, $\mathrm{pH}$, leukocytes, protein, glucose, ketone bodies, urobilinogen, bilirubin, blood, nitrites, and color were examined in the urinalysis. Microscopic examination of urinary sediments was conducted to determine amount of urine, red blood cells, white blood cells, epithelial cells, casts, and crystal in fresh urine. Samples were collected from five animals of each sex in the control and high-dose groups over a sampling period of 3 hours using metabolic cages. Total urine volume was calculated from the urine collected over a 24-hour period.

\section{Ophthalmological tests}

In the negative control and high-dose groups, eyes were examined both before grouping and during the last week of the experiment. The ocular fundus was observed using a fundus camera (Genesis, Kowa, Japan) after the pupil was dilated with a mydriatic drug (Ocu-Tropine ${ }^{\circledR}$, Samil Pharm Co Ltd, Republic of Korea).

\section{Necropsy and organ weight}

Necropsies were performed on moribund and dead animals soon after they were found. After blood samples were collected under deep anesthesia with isoflurane, the animal was euthanized by exsanguination. External surfaces, all orifices, and all organs in the cranial, thoracic, and abdominal cavities and their contents were examined. Tissues were collected from all animals and preserved for microscopic examination as described later in the histopathological examination section. In addition, the absolute and relative (organ-to-body ratio) weights of the major organs were measured in all surviving rats after they were euthanized. Liver, kidney, spleen, adrenal glands, testes, ovaries, brain, pituitary gland, lung, heart, thymus, uterus, prostate, epididymis, and submaxillary glands were included in the major organs.

\section{Hematology}

The rats were fasted overnight before necropsy. Blood was collected from the abdominal aorta under anesthesia with isoflurane. Three milliliters of blood was collected in a CBC bottle (EDTA $3 \mathrm{~K}$; BD Biosciences, San Jose, 
CA, USA) and analyzed using an autohematoanalyzer (Advia120E; Siemens). The remaining blood was transferred into Vacutainer ${ }^{\circledR}$ tubes (sodium citrate 3.2\%, BD Biosciences) and centrifuged at 3,000 rpm for 10 minutes. The plasma was separated and clotting time was determined using a coagulometer (ACL 7000; Instrumentation Laboratory, Bedford, MA, USA). The hematological parameters studied were as follows: total leukocyte and differential leukocyte (neutrophil, lymphocyte, monocyte, eosinophil, and basophil) count, total erythrocyte count, hemoglobin concentration, hematocrit, mean cell volume, mean cell hemoglobin, mean cell hemoglobin concentration, reticulocytes, platelets, prothrombin time, and activated partial thromboplastin time.

\section{Blood biochemistry}

Blood was allowed to clot for one hour at room temperature and then centrifuged at 3,000 rpm for 10 minutes to collect serum for biochemical analysis using an automatic serum analyzer (Hitachi 7060; Hitachi, Tokyo, Japan) and an electrolyte analyzer (EasyLyte Plus $\mathrm{Na} / \mathrm{K} / \mathrm{Cl}$ Analyzer; Medica, Houston, TX, USA). The parameters analyzed were as follows: total protein, albumin, albumin/globulin ratio, total bilirubin, alkaline phosphatase, aspartate aminotransferase, alanine aminotransferase, creatinine, blood urea nitrogen, total cholesterol, triglycerides, glucose, calcium, inorganic phosphorus, creatine kinase, sodium, potassium, and chloride.

\section{Histopathology}

The internal organs from all animals were collected at necropsy and fixed in 10\% neutral buffered formalin. The testes and epididymis were fixed in Bouin's solution and the eyes were fixed in Davidson's solution. Only tissues from the negative controls and high-dose groups were examined histopathologically. The following internal organs were examined: liver, kidney, adrenal gland, heart, lung, pituitary gland, spleen, seminal vesicles, testis, ovary, epididymis, prostate gland, uterus, vagina, tongue, trachea, esophagus, thymus, thyroid gland, stomach, small and large intestine, urinary bladder, submandibular gland, eyeball, skin, pancreas, sternum, mammary gland, spinal cord, femur, mesenteric lymph node, and sciatic nerve.

\section{Statistical analysis}

Body weight values, feed and water consumption data, hematological data, blood biochemistry data, and organ weight values were analyzed for homogeneity of variance using Levene's test. One-way analysis of variance was performed to evaluate the significance of differences. If the variance was homogeneous and a significant difference was identified, Scheffe's multiple comparison test was performed as a post hoc test. If the variance was not homogeneous, the data were analyzed using Dunnett's T3 test. Analysis of data from the recovery groups was performed using the Student's $t$-test. All analyses were performed using Statistical Package for the Social Sciences version 19.0 software (SPSS Inc, Chicago, IL, USA).

\section{Results}

\section{Fourteen-day dose range-finding study}

The two test particles, ie, $\mathrm{SiO}_{2}{ }^{\mathrm{EN} 20(-)}(20 \mathrm{~nm})$ and $\mathrm{SiO}_{2}^{\mathrm{EN} 100(-)}$ $(100 \mathrm{~nm})$, were orally administered to male and female Sprague-Dawley rats at doses of $500,1,000$, or $2,000 \mathrm{mg} / \mathrm{kg}$ for 14 days. There were no animal deaths related to administration of the test formulations in any group. In addition, regardless of particle size, there were no significant changes indicated by clinical observation, body weight, feed and water consumption, urinalysis, ophthalmological testing, necropsy, organ weight, or hematology or biochemistry analysis in rats of either sex. Based on the above results, the high dose for the 90 -day toxicity study was set at $2,000 \mathrm{mg} / \mathrm{kg}$ and the mid and low doses were set at 1,000 and $500 \mathrm{mg} / \mathrm{kg}$, respectively.

\section{Ninety-day repeated oral administration toxicity study Mortality and clinical signs}

Irrespective of particle size, there were no animal deaths and no treatment-related clinical signs during the experimental period for rats of either sex. However, salivation, loss of fur, and wound scratching were observed in the $\mathrm{SiO}_{2}{ }^{\mathrm{E} 20(-)}$ $2,000 \mathrm{mg} / \mathrm{kg}$ group. Specifically, salivation was observed in one male animal in the $2,000 \mathrm{mg} / \mathrm{kg}$ group on study day 47 , and loss of fur and wound scratching were observed in one male each in the $2,000 \mathrm{mg} / \mathrm{kg}$ group from study day 69 . Loss of fur was also observed in two females in the $2,000 \mathrm{mg} / \mathrm{kg}$ group from study day 68 until completion of treatment.

\section{Body weight}

Regardless of $\mathrm{SiO}_{2}$ particle size, there were no statistically significant differences in body weight between treated rats and their respective control groups, for either males or females (Figures 1 and 2).

\section{Feed consumption}

Feed consumption in male rats treated with $\mathrm{SiO}_{2}{ }^{\mathrm{EN} 20(-)}$ was significantly decreased in the $2,000 \mathrm{mg} / \mathrm{kg}$ dose group at 

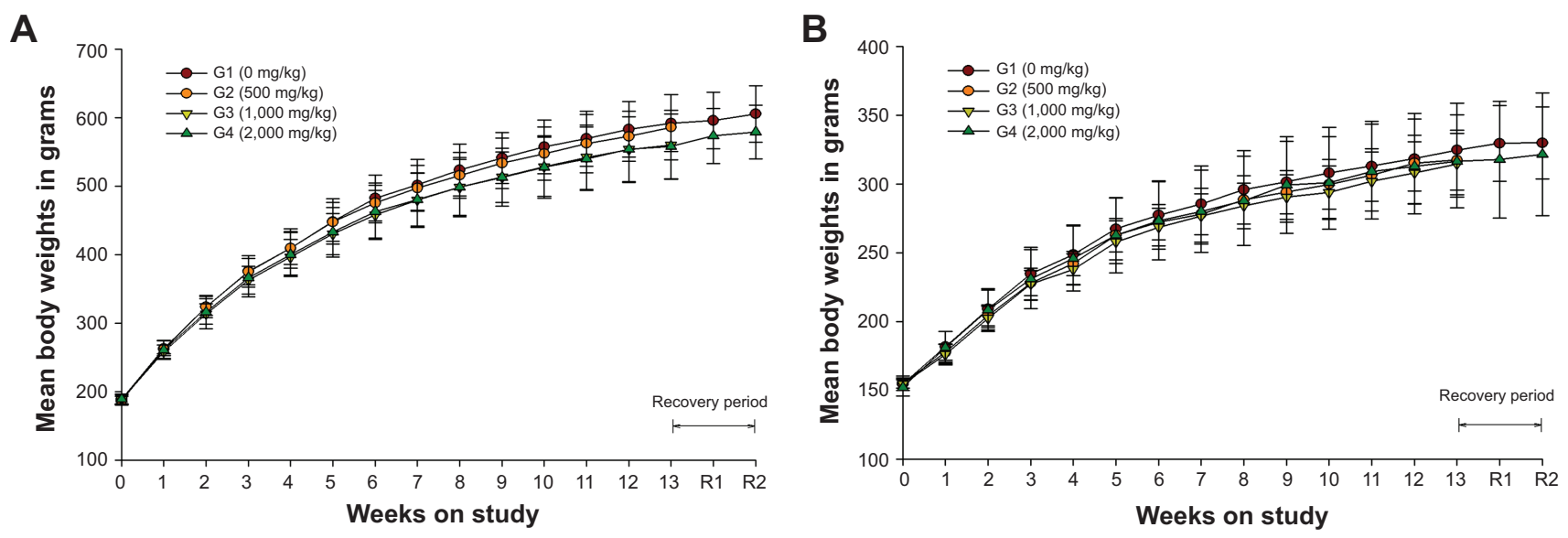

Figure I Growth curves for (A) male rats and (B) female rats administered $20 \mathrm{~nm} \mathrm{SiO}{ }_{2}$ nanoparticles $\left(\mathrm{SiO}_{2}{ }^{\mathrm{EN2}(-)}\right)$ by gavage for 90 days.

Notes: $\mathrm{SiO}_{2}{ }^{\mathrm{EN} 20(-)}$ was administered orally to Sprague-Dawley rats at doses of 500, I,000, and 2,000 $\mathrm{mg} / \mathrm{kg}$ for 90 days. Body weight was measured and recorded once per week after the start of treatment during the study period. The results are presented as the mean \pm standard deviation.

Abbreviations: GI, control; G2, 500 mg/kg treatment group; G3, I,000 mg/kg treatment group; and G4, 2,000 mg/kg treatment group.

weeks $1,2,9$, and 12 , in the $1,000 \mathrm{mg} / \mathrm{kg}$ dose group at week 1 , and in the recovery group at weeks 1 and 2 during the posttreatment period. Feed consumption was also decreased in females treated with $\mathrm{SiO}_{2}{ }^{\mathrm{EN} 20(-)}$ at a dose of $500 \mathrm{mg} / \mathrm{kg}$ at weeks 5 and 10, and also in females in the recovery group at week 1 during the post-treatment period (Table 1). In the case of $\mathrm{SiO}_{2}{ }^{\mathrm{EN} 100(-)}$, feed consumption was increased at week 1 in males given 2,000 or $1,000 \mathrm{mg} / \mathrm{kg}$, and in males given $2,000 \mathrm{mg} / \mathrm{kg}$ at week 7 and during both weeks of the post-treatment recovery period. Feed consumption was increased in females given $2,000 \mathrm{mg} / \mathrm{kg}$ at weeks 5 and 9 , and during both weeks of the post-treatment recovery period (Table 2 ).

\section{Water consumption}

Water consumption was significantly increased after treatment with $\mathrm{SiO}_{2}{ }^{\mathrm{EN} 20(-)}$ in male rats given $500 \mathrm{mg} / \mathrm{kg}$ at

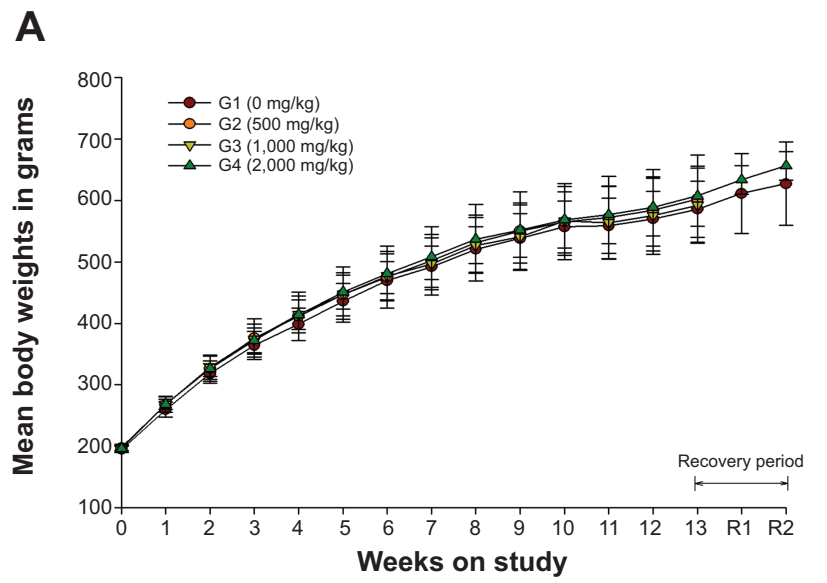

week 9 and was decreased in female rats given $2,000 \mathrm{mg} / \mathrm{kg}$ at week 6 (Table 3). In the case of $\mathrm{SiO}_{2}{ }^{\mathrm{EN} 100(-)}$, water consumption was significantly decreased in male rats given $2,000 \mathrm{mg} / \mathrm{kg}$ at weeks 9,12 , and 13 , and was increased in females given $1,000 \mathrm{mg} / \mathrm{kg}$ at weeks 1 and 13 (Table 4).

\section{Urinalysis}

Regardless of $\mathrm{SiO}_{2}$ particle size, there were no statistically significant differences in urinalysis between treated rats of either sex and their respective control groups.

\section{Necropsy findings}

Pale yellowish discoloration on the posterior surface of the left lateral lobe of the liver was observed in one male animal from the $\mathrm{SiO}_{2}{ }^{\mathrm{EN} 20(-)} 500 \mathrm{mg} / \mathrm{kg}$ group. With regard to $\mathrm{SiO}_{2}{ }^{\mathrm{EN} 100(-)}$, a small-sized right testis and epididymis

\section{B}

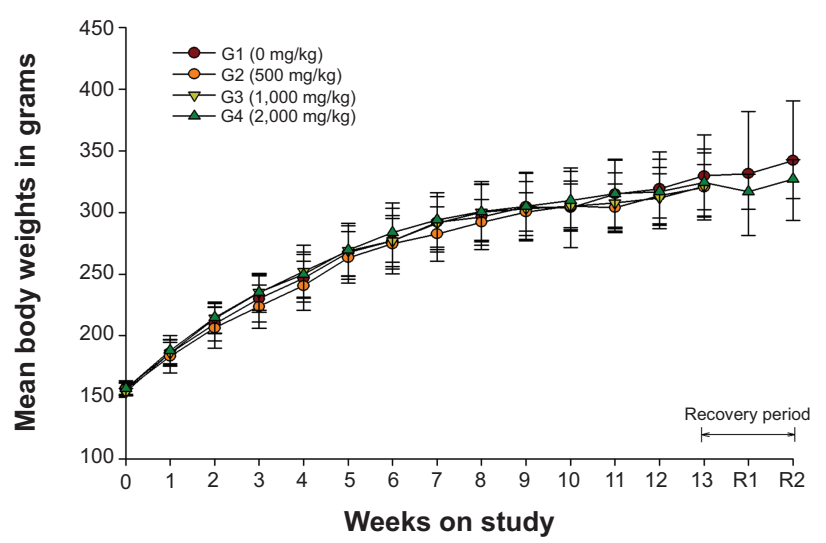

Figure 2 Growth curves for (A) male and (B) female rats administered $100 \mathrm{~nm} \mathrm{SiO}$ nanoparticles $\left(\mathrm{SiO}_{2}^{\mathrm{EN} 100(-)}\right)$ by gavage for 90 days.

Notes: $\mathrm{SiO}_{2}{ }_{\mathrm{ENI} / 00(-)}$ was orally administered to Sprague-Dawley rats at doses of 500, 1,000, and 2,000 mg/kg for 90 days. Body weight was measured and recorded once per week after the start of treatment during the study period. The results are presented as the mean \pm standard deviation.

Abbreviations: GI, control; G2, 500 mg/kg treatment group; G3, I,000 mg/kg treatment group; and G4, 2,000 mg/kg treatment group. 
Table I Feed consumption by rats in the 90 -day gavage study of $20 \mathrm{~nm} \mathrm{SiO}$, nanoparticles

\begin{tabular}{|c|c|c|c|c|c|}
\hline & & Control & $500 \mathrm{mg} / \mathrm{kg}$ & $1,000 \mathrm{mg} / \mathrm{kg}$ & $2,000 \mathrm{mg} / \mathrm{kg}$ \\
\hline Number of animals & & 15 & 10 & 10 & 15 \\
\hline \multicolumn{6}{|l|}{ Male } \\
\hline \multirow[t]{15}{*}{ Week } & 1 & $33.1 \pm 2.0$ & $31.3 \pm 2.0$ & $30.0 \pm 2.3^{b}$ & $30.2 \pm 2.1^{b}$ \\
\hline & 2 & $32.4 \pm 2.1$ & $31.6 \pm 1.9$ & $32.1 \pm 1.5$ & $29.9 \pm 1.4^{b}$ \\
\hline & 3 & $32.4 \pm 1.6$ & $30.7 \pm 0.9$ & $31.5 \pm 1.7$ & $32.0 \pm 1.6$ \\
\hline & 4 & $34.0 \pm 2.7$ & $33.8 \pm 0.8$ & $32.4 \pm \mathrm{I} .4$ & $33.5 \pm 2.6$ \\
\hline & 5 & $34.0 \pm 2.7$ & $34.4 \pm 1.5$ & $33.2 \pm 1.5$ & $31.7 \pm 2.7$ \\
\hline & 6 & $31.3 \pm 2.3$ & $32.4 \pm 2.6$ & $28.8 \pm 1.8$ & $29.8 \pm 2.7$ \\
\hline & 7 & $28.7 \pm 3.6$ & $29.1 \pm 3.2$ & $27.7 \pm 2.9$ & $27.5 \pm 1.8$ \\
\hline & 8 & $31.2 \pm 2.0$ & $30.2 \pm 2.1$ & $31.0 \pm 1.9$ & $30.5 \pm 2.2$ \\
\hline & 9 & $32.2 \pm 1.9$ & $32.5 \pm 3.0$ & $30.5 \pm 2.0$ & $29.3 \pm 1.4^{b}$ \\
\hline & 10 & $31.7 \pm 1.3$ & $32.9 \pm 2.5$ & $32.1 \pm 1.7$ & $31.5 \pm 2.2$ \\
\hline & 11 & $31.9 \pm 0.9$ & $31.3 \pm 2.4$ & $30.8 \pm 1.1$ & $31.0 \pm 2.0$ \\
\hline & 12 & $31.9 \pm 2.3$ & $30.9 \pm 2.2$ & $31.2 \pm 2.2$ & $29.1 \pm 2.7^{\mathrm{a}}$ \\
\hline & 13 & $33.7 \pm 1.0$ & $33.5 \pm 4.4$ & $32.9 \pm 3.2$ & $30.8 \pm 3.0$ \\
\hline & 14 & $30.6 \pm 2.2$ & - & - & $27.5 \pm 0.6^{\mathrm{a}}$ \\
\hline & 15 & $30.6 \pm 0.8$ & - & - & $28.5 \pm 0.1^{b}$ \\
\hline \multicolumn{6}{|l|}{ Female } \\
\hline \multirow[t]{15}{*}{ Week } & 1 & $20.8 \pm 1.8$ & $19.0 \pm 1.5$ & $22.3 \pm 1.6$ & $21.0 \pm 2.5$ \\
\hline & 2 & $22.4 \pm 2.5$ & $21.7 \pm 1.3$ & $21.2 \pm 1.2$ & $22.4 \pm 3$ \\
\hline & 3 & $21.9 \pm 2.2$ & $23.2 \pm 1.7$ & $21.8 \pm 1.6$ & $23.1 \pm 2.1$ \\
\hline & 4 & $24.5 \pm 2.2$ & $23.6 \pm 3.6$ & $25.8 \pm 6.4$ & $23.1 \pm 1.2$ \\
\hline & 5 & $22.3 \pm 2.1$ & $19.8 \pm 1.6^{a}$ & $22.9 \pm 1.9$ & $22.9 \pm 2.0$ \\
\hline & 6 & $21.5 \pm 1.7$ & $21.4 \pm 1.9$ & $22.8 \pm 2.7$ & $21.0 \pm 2.2$ \\
\hline & 7 & $18.6 \pm 1.5$ & $18.4 \pm 1.5$ & $17.6 \pm 1.5$ & $19.0 \pm 2.5$ \\
\hline & 8 & $21.9 \pm 2.6$ & $19.7 \pm 2.6$ & $20.4 \pm 2.1$ & $20.7 \pm 1.8$ \\
\hline & 9 & $20.6 \pm 3.2$ & $18.6 \pm 1.9$ & $21.3 \pm 2.0$ & $20.9 \pm 2.0$ \\
\hline & 10 & $21.2 \pm 1.0$ & $19.7 \pm 0.9^{b}$ & $20 \pm 1.3$ & $21.0 \pm 2.8$ \\
\hline & 11 & $21.3 \pm 2.1$ & $23.6 \pm 1.9$ & $20.7 \pm 2.5$ & $23.0 \pm 1.6$ \\
\hline & 12 & $27.1 \pm 18.6$ & $20.5 \pm 1.6$ & $19.9 \pm 1.6$ & $19.9 \pm 1.4$ \\
\hline & 13 & $23.8 \pm 1.7$ & $21.7 \pm 2.7$ & $23.0 \pm 2.0$ & $21.8 \pm 2.1$ \\
\hline & 14 & $27 . I \pm 4.4$ & - & - & $16.5 \pm 1.4^{b}$ \\
\hline & 15 & $25.0 \pm 5.5$ & - & - & $29.5 \pm 5.7$ \\
\hline
\end{tabular}

Notes: $\mathrm{a}<0.05$, and $\mathrm{b} P<0.0 \mathrm{I}$, significantly different from vehicle control, by Scheffe's test; data are given as the mean \pm standard deviation ( $\mathrm{g} / \mathrm{rat} / \mathrm{day}$ ).

were observed in one male from the $500 \mathrm{mg} / \mathrm{kg}$ group. A light yellow discoloration of the left lateral lobe of the liver (about $1 \mathrm{~mm}$ diameter), and a light yellowcolored cyst with adjacent fat near the right kidney were also observed in another male in the $1,000 \mathrm{mg} / \mathrm{kg}$ group. In addition, a small-sized left ovary was observed in one female from the $2,000 \mathrm{mg} / \mathrm{kg}$ recovery group.

\section{Organ weight}

For $\mathrm{SiO}_{2}{ }^{\mathrm{EN} 20(-)}$, the relative liver weight was significantly decreased in male rats from the $2,000 \mathrm{mg} / \mathrm{kg}$ group. In addition, both absolute and relative lung weights were increased in male rats from the $2,000 \mathrm{mg} / \mathrm{kg}$ recovery group in comparison with the control group. In the case of $\mathrm{SiO}_{2}{ }^{\mathrm{EN} 100(-)}$, the absolute weights of the kidney, lung, and submandibular glands were significantly increased in male rats from the $2,000 \mathrm{mg} / \mathrm{kg}$ recovery group, and the relative weights of the kidney and lung were significantly increased in the same group compared with the control group. Both absolute and relative ovary weights were significantly decreased in female rats from the $2,000 \mathrm{mg} / \mathrm{kg}$ recovery group (Tables 5 and 6).

\section{Hematology}

Lymphocytes in male rats from the $\mathrm{SiO}_{2}{ }^{\mathrm{EN} 20(-)} 2,000 \mathrm{mg} / \mathrm{kg}$ recovery group were significantly increased when compared with the control group (Table 7). However, there were no statistically significant differences in the groups treated with $\mathrm{SiO}_{2}^{\mathrm{EN} 100(-)}$.

\section{Blood biochemistry}

There were no statistically significant changes in blood biochemistry data related to administration of $\mathrm{SiO}_{2}{ }^{\mathrm{EN} 20(-)}$. 
Table 2 Feed consumption by rats in the 90-day gavage study of $100 \mathrm{~nm} \mathrm{SiO}$, nanoparticles

\begin{tabular}{|c|c|c|c|c|c|}
\hline & & Control & $500 \mathrm{mg} / \mathrm{kg}$ & $1,000 \mathrm{mg} / \mathrm{kg}$ & $2,000 \mathrm{mg} / \mathrm{kg}$ \\
\hline Number of animals & & 15 & 10 & 10 & 15 \\
\hline \multicolumn{6}{|l|}{ Male } \\
\hline \multirow[t]{15}{*}{ Week } & 1 & $27.0 \pm 3.2$ & $30.1 \pm 2.7^{\mathrm{a}}$ & $30.2 \pm 2.3^{\mathrm{a}}$ & $30.2 \pm 2.4$ \\
\hline & 2 & $31.3 \pm 3.5$ & $33.1 \pm 2.6$ & $32.4 \pm 3.3$ & $33.6 \pm 1.9$ \\
\hline & 3 & $31.4 \pm 3.5$ & $32.1 \pm 4.0$ & $32.4 \pm 3.0$ & $32.9 \pm 1.9$ \\
\hline & 4 & $3 I .1 \pm 2.8$ & $33.6 \pm 3.0$ & $32.3 \pm 1.7$ & $32.2 \pm 2.1$ \\
\hline & 5 & $34 . I \pm 4.6$ & $31.6 \pm 2.5$ & $33.1 \pm 2.7$ & $34.0 \pm 1.7$ \\
\hline & 6 & $31.2 \pm 3.9$ & $32.4 \pm 2.5$ & $32.4 \pm 3.6$ & $33.1 \pm 2.4$ \\
\hline & 7 & $32.0 \pm 3.3$ & $35.1 \pm 3.8$ & $34.0 \pm 4.7$ & $36.0 \pm 2.7^{\mathrm{a}}$ \\
\hline & 8 & $31.8 \pm 2.5$ & $31.2 \pm 2.7$ & $32.6 \pm 3.1$ & $32.0 \pm 2.0$ \\
\hline & 9 & $30.2 \pm 2.6$ & $31.5 \pm 1.1$ & $28.5 \pm 1.6$ & $29.6 \pm 1.4$ \\
\hline & 10 & $29.7 \pm 2.5$ & $25.6 \pm 6.4$ & $26.7 \pm 1.7$ & $27.8 \pm 2.1$ \\
\hline & II & $29.6 \pm 3.2$ & $31.5 \pm 2.0$ & $29.6 \pm 3.8$ & $30.0 \pm 1.7$ \\
\hline & 12 & $28.5 \pm 2.7$ & $28.9 \pm 1.5$ & $28.7 \pm 4.4$ & $28.5 \pm 1.6$ \\
\hline & 13 & $28.6 \pm 2.6$ & $27.5 \pm 2.2$ & $25.6 \pm 3.5$ & $27.1 \pm 2.5$ \\
\hline & 14 & $31.0 \pm 1.1$ & - & - & $30.6 \pm 0.7$ \\
\hline & 15 & $24.2 \pm 0.1$ & - & - & $28.7 \pm 1.7^{b}$ \\
\hline \multicolumn{6}{|l|}{ Female } \\
\hline \multirow[t]{15}{*}{ Week } & I & $19.2 \pm 1.8$ & $17.7 \pm 1.7$ & $21.3 \pm 2.1$ & $19.7 \pm 1.4$ \\
\hline & 2 & $21.6 \pm 2.9$ & $22.1 \pm 2.9$ & $22.6 \pm 1.3$ & $21.9 \pm 1.6$ \\
\hline & 3 & $22.1 \pm 1.4$ & $22.5 \pm 2.3$ & $21.1 \pm 4.6$ & $21.5 \pm 3.3$ \\
\hline & 4 & $22.4 \pm 2.5$ & $21.8 \pm 1.9$ & $22.3 \pm 4.5$ & $22.9 \pm 1.2$ \\
\hline & 5 & $22.2 \pm 1.5$ & $20.1 \pm 2.6$ & $24.2 \pm 2.5$ & $24.8 \pm 1.8^{b}$ \\
\hline & 6 & $23.0 \pm 2.9$ & $22.2 \pm 1.9$ & $22.5 \pm 2.5$ & $21.9 \pm 3.0$ \\
\hline & 7 & $25.1 \pm 1.4$ & $26.6 \pm 1.6$ & $26.2 \pm 1.3$ & $26.2 \pm 3.5$ \\
\hline & 8 & $23.3 \pm 1.4$ & $22.0 \pm 0.7$ & $23.1 \pm 3.5$ & $21.1 \pm 2.2$ \\
\hline & 9 & $17.8 \pm 3.7$ & $17.0 \pm 2.6$ & $18.4 \pm 3.0$ & $21.6 \pm 2.0^{\mathrm{a}}$ \\
\hline & 10 & $18.3 \pm 1.4$ & $16.4 \pm 1.9$ & $17.4 \pm 2.3$ & $17.1 \pm 3.8$ \\
\hline & II & $20.1 \pm 1.8$ & $20.0 \pm 2.1$ & $18.9 \pm 2.1$ & $20.3 \pm 1.5$ \\
\hline & 12 & $19.0 \pm 1.4$ & $\mid 8.4 \pm 1.5$ & $20.0 \pm 2.4$ & $19.2 \pm 2.1$ \\
\hline & 13 & $19.1 \pm 1.8$ & $|7.8 \pm I|$. & $19.7 \pm 4.1$ & $19.5 \pm 2.1$ \\
\hline & 14 & $18.2 \pm 1.1$ & - & - & $21.5 \pm 1.3^{b}$ \\
\hline & 15 & $15.8 \pm 0.7$ & - & - & $18.1 \pm 0.1^{b}$ \\
\hline
\end{tabular}

Notes: a $P<0.05$ and ${ }^{b} P<0.01$, significantly different from vehicle control, by Scheffe's test; data are given as the mean \pm standard deviation ( $g /$ rat $/$ day).

However, aspartate aminotransferase and creatine kinase levels were significantly decreased in female rats from the $\mathrm{SiO}_{2}{ }^{\mathrm{EN} 100(-)} 2,000 \mathrm{mg} / \mathrm{kg}$ recovery group compared with those from the control group (Table 7).

\section{Histopathology}

Remarkable changes in the $\mathrm{SiO}_{2}{ }^{\mathrm{EN} 20(-)}$ treatment group when compared with the negative control groups included granulomatous and bronchioalveolar inflammation. Granulomatous inflammation was observed in one male rat from the $1,000 \mathrm{mg} / \mathrm{kg}$ group and two from the $2,000 \mathrm{mg} / \mathrm{kg}$ group. Chronic bronchioalveolar inflammation was observed in one male rat from the $2,000 \mathrm{mg} / \mathrm{kg}$ group. However, there were no treatment-related histopathological changes in rats treated with $\mathrm{SiO}_{2}{ }^{\mathrm{EN} 100(-)}$.

\section{Discussion}

The present study investigated the potential toxic effects of colloidal silica and determined the NOAEL and target organs after 90 days of repeated oral administration of $\mathrm{SiO}_{2} \mathrm{NPs}$ in Sprague-Dawley rats following OECD test guideline 408. This chronic study was intended to provide information for establishing safety criteria with regard to human exposure and the major toxic effects of $\mathrm{SiO}_{2}$ NPs. ${ }^{16}$ Size-dependent toxicity of $20 \mathrm{~nm}$ and $100 \mathrm{~nm} \mathrm{SiO}_{2}$ NPs was examined, considering that particle size could be one of the key factors in nanotoxicity. 
Table 3 Water consumption by rats in the 90-day gavage study of $20 \mathrm{~nm} \mathrm{SiO}$ nanoparticles

\begin{tabular}{|c|c|c|c|c|c|}
\hline & & Control & $500 \mathrm{mg} / \mathrm{kg}$ & $1,000 \mathrm{mg} / \mathrm{kg}$ & $2,000 \mathrm{mg} / \mathrm{kg}$ \\
\hline Number of animals & & 15 & 10 & 10 & 15 \\
\hline \multicolumn{6}{|l|}{ Male } \\
\hline \multirow[t]{15}{*}{ Week } & I & $52.8 \pm 14$ & $52.8 \pm 9.7$ & $45.7 \pm 5.4$ & $48.6 \pm 9.8$ \\
\hline & 2 & $43.5 \pm 3.1$ & $50.2 \pm 7.7$ & $49.5 \pm 3.9$ & $47.0 \pm 7.1$ \\
\hline & 3 & $49.3 \pm 5.4$ & $51.2 \pm 13.7$ & $49.4 \pm 8.7$ & $46.1 \pm 7.9$ \\
\hline & 4 & $43.8 \pm 2.7$ & $47.2 \pm 5.3$ & $49.9 \pm 6.0$ & $47.6 \pm 9.0$ \\
\hline & 5 & $47.8 \pm 7.3$ & $51.0 \pm 5.0$ & $47.0 \pm 3.9$ & $42.3 \pm 6.1$ \\
\hline & 6 & $40.5 \pm 4.8$ & $41.0 \pm 2.4$ & $38.6 \pm 3.1$ & $39.1 \pm 7.2$ \\
\hline & 7 & $40.8 \pm 6.7$ & $42.0 \pm 4.7$ & $44.1 \pm 12.2$ & $43.2 \pm 15.4$ \\
\hline & 8 & $39.7 \pm 7.1$ & $44.7 \pm 3.5$ & $38.8 \pm 6.4$ & $40.2 \pm 10.0$ \\
\hline & 9 & $39.6 \pm 4.5$ & $44.2 \pm 2.3^{\mathrm{a}}$ & $43.5 \pm 7.5$ & $37.3 \pm 6.7$ \\
\hline & 10 & $37.2 \pm 1.8$ & $39.2 \pm 4.3$ & $37.9 \pm 4.9$ & $39.1 \pm 7.0$ \\
\hline & II & $39.2 \pm 2.8$ & $40.8 \pm 4.8$ & $43.9 \pm 5.7$ & $40.4 \pm 7.4$ \\
\hline & 12 & $44.6 \pm 5.4$ & $42.6 \pm 4.2$ & $42.6 \pm 6.4$ & $45.5 \pm 13.7$ \\
\hline & 13 & $43.9 \pm 6.1$ & $46.8 \pm 4.9$ & $45.6 \pm 4.4$ & $42.4 \pm 12.7$ \\
\hline & 14 & $34.3 \pm 0.1$ & - & - & $38.0 \pm 4.7$ \\
\hline & 15 & $36.4 \pm 1.6$ & - & - & $47.4 \pm 9.1$ \\
\hline \multicolumn{6}{|l|}{ Female } \\
\hline \multirow[t]{15}{*}{ Week } & 1 & $40.6 \pm 9.2$ & $50.3 \pm 16.5$ & $43.4 \pm 6.9$ & $37.3 \pm 8.0$ \\
\hline & 2 & $39.3 \pm 3.6$ & $41.9 \pm 9.5$ & $33.2 \pm 3.8$ & $35.5 \pm 4.5$ \\
\hline & 3 & $40.6 \pm 8.4$ & $45.2 \pm 11.7$ & $34.4 \pm 6.8$ & $35.0 \pm 5.4$ \\
\hline & 4 & $38.8 \pm 6.3$ & $36.4 \pm 4.3$ & $31.5 \pm 4.6$ & $33.6 \pm 7.7$ \\
\hline & 5 & $33.5 \pm 4.5$ & $31.1 \pm 4.9$ & $32.1 \pm 8.3$ & $29.5 \pm 4.7$ \\
\hline & 6 & $33.5 \pm 4.1$ & $29.4 \pm 4.4$ & $33.4 \pm 8.3$ & $27.7 \pm 4.8^{\mathrm{a}}$ \\
\hline & 7 & $28.4 \pm 4.2$ & $30.7 \pm 5.0$ & $26.3 \pm 2.2$ & $31.4 \pm 13.9$ \\
\hline & 8 & $35.2 \pm 4.9$ & $32.3 \pm 5.9$ & $34.3 \pm 6.3$ & $35.3 \pm 11.5$ \\
\hline & 9 & $34.3 \pm 4.3$ & $29.8 \pm 5.7$ & $32.7 \pm 7.6$ & $30.4 \pm 5.1$ \\
\hline & 10 & $31.0 \pm 3.3$ & $28.6 \pm 4.0$ & $31.6 \pm 8.0$ & $32.4 \pm 9.7$ \\
\hline & II & $32.3 \pm 4.9$ & $34.1 \pm 4.7$ & $29.3 \pm 3.0$ & $32.3 \pm 6.5$ \\
\hline & 12 & $34.3 \pm 3.5$ & $32.6 \pm 4.3$ & $28.7 \pm 2.7$ & $36.2 \pm 17.3$ \\
\hline & 13 & $40.1 \pm 7.6$ & $35.1 \pm 5.8$ & $36.0 \pm 5.8$ & $36.9 \pm 7.4$ \\
\hline & 14 & $38.3 \pm 2.8$ & - & - & $32.0 \pm 12.1$ \\
\hline & 15 & $35.7 \pm 3.2$ & - & - & $32.8 \pm 4.3$ \\
\hline
\end{tabular}

Notes: ${ }^{\mathrm{P}}<0.05$, significantly different from control, by Scheffe's test; data are given as the mean \pm standard deviation ( $g /$ rat $/$ day).

A recent report indicated that oral administration of $5,000 \mathrm{mg} / \mathrm{mL}$ mesoporous $\mathrm{SiO}_{2}$ NPs did not result in death, abnormal behavior, or any acute toxicity in mice, suggesting that a dose of $5,000 \mathrm{mg} / \mathrm{mL}$ could be the maximum tolerated dose for oral administration. ${ }^{15}$ Further, our preliminary acute oral pharmacokinetic absorption study showed no significant effects at doses of $2,000 \mathrm{mg} / \mathrm{kg}$. Moreover, on the basis of toxicity studies, the OECD guideline recommends maximum doses for pharmaceuticals and food additives as $2,000 \mathrm{mg} / \mathrm{kg}$ and 5,000 mg/kg, respectively. ${ }^{18}$ Considering the differences in animal species and experimental durations used in the earlier studies, we selected 2,000 $\mathrm{mg} / \mathrm{kg}$ for the high dose in our 14-day dose range-finding study, with 1,000 and $500 \mathrm{mg} / \mathrm{kg}$ as the middle and low doses, respectively. No animal deaths or significant changes were observed in any of parameters monitored during our 14-day dose range-finding study. Also, the OECD test guideline suggests that the highest dose level should be chosen with the aim to induce toxicity without death or severe suffering, and two-fold intervals were selected as optimal for setting the descending dose levels in a repeated-dose 90-day oral toxicity study in rodents. ${ }^{16}$ Therefore, the three test dose levels of 500, 1,000 and 2,000 mg/kg were selected for the 90-day toxicity study.

In the 90-day repeated oral administration study, there were no deaths and no treatment-related clinical signs of toxicity during the experimental period in rats of either sex, irrespective of particle size. Salivation, loss of fur, and wound scratching were observed in very few cases at $2,000 \mathrm{mg} / \mathrm{kg}$ of $\mathrm{SiO}_{2}^{\mathrm{EN} 20(-)}$, but were not considered to be treatment-related, given that they did not show any dose-dependency among the treatment groups and were observed only sporadically. 
Table 4 Water consumption by rats in the 90 -day gavage study of $100 \mathrm{~nm} \mathrm{SiO}{ }_{2}$ nanoparticles

\begin{tabular}{|c|c|c|c|c|c|}
\hline & & Control & $500 \mathrm{mg} / \mathrm{kg}$ & $1,000 \mathrm{mg} / \mathrm{kg}$ & $2,000 \mathrm{mg} / \mathrm{kg}$ \\
\hline Number of animals & & 15 & 10 & 10 & 15 \\
\hline \multicolumn{6}{|l|}{ Male } \\
\hline \multirow[t]{15}{*}{ Week } & I & $36.4 \pm 5.4$ & $39.6 \pm 6.8$ & $38.0 \pm 2.4$ & $36.7 \pm 4.3$ \\
\hline & 2 & $40.3 \pm 5.7$ & $4 I .4 \pm 6.1$ & $39.8 \pm 4.0$ & $41.2 \pm 4.8$ \\
\hline & 3 & $41.6 \pm 4.7$ & $42.0 \pm 6.2$ & $43.4 \pm 5.8$ & $40.2 \pm 3.7$ \\
\hline & 4 & 44. $I \pm 7.6$ & $41.2 \pm 7.2$ & $42.5 \pm 2.5$ & $40.9 \pm 4.6$ \\
\hline & 5 & $38.2 \pm 7.8$ & $43.0 \pm 6.7$ & $44.2 \pm 3.4$ & $41.8 \pm 5.4$ \\
\hline & 6 & $44.8 \pm 8.1$ & $40.5 \pm 5.2$ & $46.0 \pm 6.9$ & $38.2 \pm 4.2$ \\
\hline & 7 & $43.9 \pm 7.0$ & $44.8 \pm 8.8$ & $45.2 \pm 3.7$ & $43.6 \pm 6.5$ \\
\hline & 8 & $42.8 \pm 9.8$ & $39.4 \pm 8.9$ & $42.0 \pm 4.9$ & $37.0 \pm 3.7$ \\
\hline & 9 & $42.7 \pm 5.0$ & $42.1 \pm 6.5$ & $40.5 \pm 1.2$ & $35.0 \pm 5.9^{b}$ \\
\hline & 10 & $42.0 \pm 9.3$ & $37.5 \pm 7.9$ & $36.8 \pm 4.5$ & $36.7 \pm 7.7$ \\
\hline & II & $42.0 \pm 7.8$ & $40.9 \pm 10.1$ & $42.2 \pm 5.4$ & $37.5 \pm 4.4$ \\
\hline & 12 & $47.1 \pm 5.8$ & $42.8 \pm 8.1$ & $42 . I \pm 4.6$ & $36.2 \pm 5.0^{\mathrm{b}}$ \\
\hline & 13 & $46.6 \pm 6.4$ & $42.6 \pm 7.9$ & $40.5 \pm 6.2$ & $37.0 \pm 6.5^{b}$ \\
\hline & 14 & $46.4 \pm 8.3$ & - & - & $36.9 \pm 5.1$ \\
\hline & 15 & $47.4 \pm 10.9$ & - & - & $35.4 \pm 4.1$ \\
\hline \multicolumn{6}{|l|}{ Female } \\
\hline \multirow[t]{15}{*}{ Week } & I & $25.2 \pm 3.7$ & $25.5 \pm 3.1$ & $30.5 \pm 3.1^{b}$ & $27.1 \pm 2.5$ \\
\hline & 2 & $28.0 \pm 7.1$ & $29.4 \pm 2.6$ & $33.3 \pm 2.7$ & $29.5 \pm 6.0$ \\
\hline & 3 & $30.1 \pm 5.4$ & $30.7 \pm 2.8$ & $32.5 \pm 3.3$ & $28.2 \pm 4.8$ \\
\hline & 4 & $32.0 \pm 9.9$ & $31.6 \pm 2.0$ & $32.1 \pm 4.9$ & $31.3 \pm 4.8$ \\
\hline & 5 & $30.7 \pm 7.5$ & $27.1 \pm 5.4$ & $34.7 \pm 3.8$ & $31.6 \pm 3.8$ \\
\hline & 6 & $33.6 \pm 8.7$ & $33.9 \pm 5.2$ & $33.4 \pm 3.3$ & $31.2 \pm 5.8$ \\
\hline & 7 & $38.1 \pm 9.2$ & $37.7 \pm 3.1$ & $38.6 \pm 6.4$ & $35.4 \pm 5.5$ \\
\hline & 8 & $31.3 \pm 6.2$ & $30.8 \pm 4.1$ & $32.9 \pm 5.1$ & $28.2 \pm 4.5$ \\
\hline & 9 & $30.4 \pm 5.0$ & $26.6 \pm 4.8$ & $31.2 \pm 8.5$ & $32.0 \pm 6.3$ \\
\hline & 10 & $27.1 \pm 6.4$ & $24.3 \pm 4.0$ & $30.0 \pm 5.6$ & $23.9 \pm 5.6$ \\
\hline & II & $30.7 \pm 6.8$ & $30.2 \pm 3.7$ & $30.8 \pm 3.8$ & $29.7 \pm 3.3$ \\
\hline & 12 & $30.7 \pm 4.6$ & $33.9 \pm 6.2$ & $36.0 \pm 5.0$ & $29.0 \pm 2.8$ \\
\hline & 13 & $27.9 \pm 4.5$ & $32.5 \pm 5.5$ & $36.5 \pm 3.5^{\mathrm{a}}$ & $29.9 \pm 5.5$ \\
\hline & 14 & $35.0 \pm 6.2$ & - & - & $33.0 \pm 0.4$ \\
\hline & 15 & $35.3 \pm 6.1$ & - & - & $32.3 \pm 1.7$ \\
\hline
\end{tabular}

Notes: ${ }^{a} P<0.05$ and ${ }^{b} P<0.0$ I, significantly different from vehicle control, by Scheffe's test; data are given as the mean \pm standard deviation ( $g /$ rat $/$ day).

Similarly, although significant changes in feed and water consumption were observed for both sexes in all treatment groups, they were not considered to be treatment-related as they did not show consistent dose-dependency over time after initiation of treatment and occurred only sporadically.
Necropsy findings were significant in the liver, kidney, and ovary in rats in the $\mathrm{SiO}_{2} \mathrm{NP}$ treatment groups. The absolute and relative weights of the lung and liver were significantly changed in the $\mathrm{SiO}_{2}{ }^{\mathrm{EN} 20(-)}$ treatment groups, and the absolute weights of the kidney, lung, and submandibular

Table 5 Organ weights and organ weight to body weight ratios of male rats in the 90-day gavage study (main group) of $20 \mathrm{~nm}$ $\mathrm{SiO}_{2}$ nanoparticles*

\begin{tabular}{|c|c|c|c|c|}
\hline & Control & 500 mg/kg & I,000 mg/kg & $2,000 \mathrm{mg} / \mathrm{kg}$ \\
\hline Number of animals & 10 & 10 & 10 & 10 \\
\hline \multicolumn{5}{|l|}{ Male } \\
\hline Necropsy body weight & $565.9 \pm 43.4$ & $553.7 \pm 45.1$ & $529.1 \pm 48.4$ & $526.6 \pm 48.9$ \\
\hline \multicolumn{5}{|l|}{ Liver } \\
\hline Absolute (g) & $14.70 \pm 1.90$ & $13.65 \pm 1.26$ & $13.11 \pm 1.94$ & $12.59 \pm 1.71$ \\
\hline Relative (\%) & $2.59 \pm 0.18$ & $2.47 \pm 0.14$ & $2.47 \pm 0.16$ & $2.38 \pm 0.1 \mathrm{I}^{\mathrm{a}}$ \\
\hline
\end{tabular}

Notes: *Organ (absolute) weights and body weights are given in grams: organ weight to body (relative) weights are given as mg organ weight/g body weight (mean \pm standard deviation); ${ }^{P}<0.05$ significantly different from control, by Scheffe's test. 
Table 6 Organ weights and organ weight to body weight ratios for the recovery group in the 90 -day gavage study of $\mathrm{SiO}_{2}$ nanoparticles*

\begin{tabular}{|c|c|c|}
\hline & Control & $2,000 \mathrm{mg} / \mathrm{kg}$ \\
\hline Number of animals & 5 & 5 \\
\hline \multicolumn{3}{|l|}{$\mathrm{SiO}_{2}^{\mathrm{EN} 20(-)}$} \\
\hline \multicolumn{3}{|l|}{ Male } \\
\hline Necropsy body weight & $569.8 \pm 38.4$ & $545.9 \pm 35.0$ \\
\hline \multicolumn{3}{|l|}{ Lung } \\
\hline Absolute (g) & $1.61 \pm 0.07$ & $1.8 \mathrm{I} \pm 0.12^{\mathrm{a}}$ \\
\hline Relative (\%) & $0.28 \pm 0.02$ & $0.33 \pm 0.02^{\mathrm{a}}$ \\
\hline \multicolumn{3}{|l|}{$\mathrm{SiO}_{2}{ }_{\text {EN100(-) }}$} \\
\hline \multicolumn{3}{|l|}{ Male $^{2}$} \\
\hline Necropsy body weight & $577.4 \pm 60.5$ & $603.3 \pm 22.0$ \\
\hline \multicolumn{3}{|l|}{ Kidney } \\
\hline Absolute (g) & $3.27 \pm 0.21$ & $3.69 \pm 0.2 \mathrm{I}^{\mathrm{a}}$ \\
\hline Relative (\%) & $0.57 \pm 0.03$ & $0.6 \mathrm{I} \pm 0.02^{\mathrm{a}}$ \\
\hline \multicolumn{3}{|l|}{ Lung } \\
\hline Absolute (g) & $1.62 \pm 0.09$ & $1.93 \pm 0.08^{\mathrm{a}}$ \\
\hline Relative (\%) & $0.28 \pm 0.02$ & $0.32 \pm 0.02^{\mathrm{a}}$ \\
\hline \multicolumn{3}{|l|}{ Submaxillary gland } \\
\hline Absolute (g) & $0.78 \pm 0.04$ & $0.96 \pm 0.12^{\mathrm{a}}$ \\
\hline Relative (\%) & $0.14 \pm 0.01$ & $0.16 \pm 0.02$ \\
\hline \multicolumn{3}{|l|}{ Female } \\
\hline Necropsy body weight & $303.9 \pm 47.8$ & $304.9 \pm 16.9$ \\
\hline \multicolumn{3}{|l|}{ Ovary } \\
\hline Absolute (g) & $0.094 \pm 0.009$ & $0.066 \pm 0.022^{\mathrm{a}}$ \\
\hline Relative (\%) & $0.0314 \pm 0.0040$ & $0.0217 \pm 0.0069^{2}$ \\
\hline
\end{tabular}

Notes: *Organ (absolute) weights and body weights are given in grams: organ weight to body (relative) weights are given as $\mathrm{mg}$ organ weights/g body weight (mean \pm standard deviation); ${ }^{a} P<0.05$, significantly different from control by Scheffe's test.

Abbreviations: $\mathrm{SiO}_{2}{ }^{\mathrm{EN2O}(-)}, 20 \mathrm{~nm} \mathrm{SiO}$ nanoparticle treatment group; $\mathrm{SiO}_{2}{ }^{\mathrm{ENIO0}(-)}$, $100 \mathrm{~nm} \mathrm{SiO}$, nanoparticle treatment group.

gland, and the relative weights of the kidney, lung, and ovary were changed in the $\mathrm{SiO}_{2}{ }^{\mathrm{EN} 100(-)}$ treatment groups when compared with their respective control groups. However, these changes in necropsy findings and organ weights were not considered to be treatment-related, because they did not show dose-dependency and did not correspond with histopathological observations.

To summarize the histopathological findings, no $\mathrm{SiO}_{2} \mathrm{NP}$ treatment-related changes were observed in appearance or morphology in the treatment groups, regardless of particle size, with only granulomatous and bronchioalveolar inflammation observed in the $\mathrm{SiO}_{2}{ }^{\mathrm{EN} 20(-)}$ treatment groups. These lesions were observed in only four cases, and seemed to be minimal to mild in severity; the other animals did not show any treatment-related effects in the lung, which was not considered to be the affect lesion by the test material. Similarly, Fu et al reported that different routes of exposure to mesoporous $\mathrm{SiO}_{2} \mathrm{NPs}$, including intravenous, oral, hypodermic, and intramuscular administration, did not result in
Table 7 Hematology and blood biochemistry data for the recovery group in the 90 -day gavage study of $\mathrm{SiO}_{2}$ nanoparticles

\begin{tabular}{|c|c|c|}
\hline & Control & $2,000 \mathrm{mg} / \mathrm{kg}$ \\
\hline Number of animals & 5 & 5 \\
\hline \multicolumn{3}{|l|}{ Males in $\mathrm{SiO}_{2}^{\mathrm{EN2O}(-)}$} \\
\hline Lymphocytes (\%) & $71.7 \pm 1.8$ & $75.1 \pm 2.6^{\mathrm{a}}$ \\
\hline \multicolumn{3}{|l|}{ Females in $\mathrm{SiO}_{2}{ }^{\mathrm{EN} 100(-)}$} \\
\hline AST (U/L) & $128 \pm 36$ & $102 \pm 2 I^{b}$ \\
\hline CK (IU/L) & $631 \pm 270$ & $400 \pm 304^{a}$ \\
\hline
\end{tabular}

Notes: Data are given as the mean \pm standard deviation; ${ }^{\mathrm{P}} \mathrm{P}<0.05$ and ${ }^{\mathrm{b} P}<0.0 \mathrm{l}$, significantly different from control, by Scheffe's test.

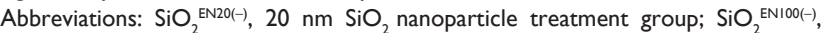
$100 \mathrm{~nm} \mathrm{SiO}{ }_{2}$ nanoparticle treatment group; AST, aspartate aminotransferase; CK, creatine kinase.

any histopathological changes or lesions in the liver, spleen, kidney, or lung at 24 hours and 7 days after administration in mice. $^{15}$

In the present study, treatment-related clinical change or target organ were not observed after 90 days of oral

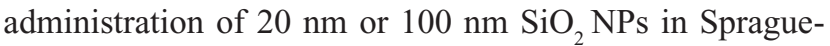
Dawley rats of either sex. Moreover, when comparing our observations according to $\mathrm{SiO}_{2} \mathrm{NP}$ size, no difference in toxicity resulting from long-term exposure to the particles was seen. Of note, a recent study reported no difference in plasma concentration-time curves in rats after single oral administration of $\mathrm{SiO}_{2} \mathrm{NPs}$ at doses of 500 and $1,000 \mathrm{mg} / \mathrm{kg}$ using similar particle sizes, ie, $20 \mathrm{~nm}$ and $100 \mathrm{~nm} .{ }^{19}$ These results coincide with the similar physicochemical properties of the test agents used in the present study. Similar to our results indicating an absence of toxic effects during the experimental period, a number of other studies have also demonstrated no adverse effects of $\mathrm{SiO}_{2} \mathrm{NPs}$ or only limited minor toxic effects. For example, some studies have reported $\mathrm{SiO}_{2}$ NPs to have negligible cytotoxicity, and that they did not show any cytotoxicity or genotoxicity in human cancer cells. ${ }^{20,21}$ Guo et al reported that intraperitoneal injection of $\mathrm{SiO}_{2}$ NPs showed low toxicity with regard to histopathological changes and serum biochemical parameters, and that $\mathrm{SiO}_{2}$ NPs did not induce oxidative stress in mice after 7 days of injection. ${ }^{22}$ Another intraperitoneal injection study in mice indicated that exposure to colloidal $\mathrm{SiO}_{2} \mathrm{NPs}$ for a period of 4 weeks did not have any effect on immunological parameters, such as serum immunoglobulin $\mathrm{G}$ and immunoglobulin M levels, or splenic lymphocyte numbers. ${ }^{23}$ In addition, when rats were exposed to $\mathrm{SiO}_{2} \mathrm{NPs}$ via intratracheal instillation, no influence on markers of oxidative stress, including superoxide dismutase, inducible nitric oxide synthase, and cyclo-oxygenase type 2 enzymes, was found at 24 hours, 7 days, or 30 days after instillation. ${ }^{24}$ Further, Ivanov et al 
suggested that $\mathrm{SiO}_{2}$ NPs were biocompatible nanomaterials with regard to acute toxicity upon intravenous administration in rats after 5, 21, and 60 days. ${ }^{25}$ Thus, we could speculate that both $20 \mathrm{~nm}$ and $100 \mathrm{~nm}$ colloidal $\mathrm{SiO}_{2}$ NPs would have minor acute and chronic toxicity, although additional intensive mechanistic studies would be required based on their physicochemical properties.

\section{Conclusion}

In conclusion, under the conditions of this study, in which $500,1,000$, and $2,000 \mathrm{mg} / \mathrm{kg}$ doses of two different sized colloidal $\mathrm{SiO}_{2}$ particles $(20 \mathrm{~nm}$ and $100 \mathrm{~nm}$ ) were repeatedly administered by gavage for 90 days in Sprague-Dawley rats, neither test material had a toxic effect on the organs and tissues studied. Therefore, the NOAEL would be more than $2,000 \mathrm{mg} / \mathrm{kg}$, and no target organs were identified in rats of either sex.

\section{Acknowledgments}

This research was supported by a grant (10182MFDS991) from the Ministry of Food and Drug Safety in 2011. It was also supported by the Research-Driven Hospital Project of Korea University Anam Hospital accredited by the Korean Government Ministry of Health and Welfare 2013.

\section{Disclosure}

The authors report no conflicts of interest in this work.

\section{References}

1. Bottini M, D’Annibale F, Magrini A, et al. Quantum dot-doped silica nanoparticles as probes for targeting of T-lymphocytes. Int J Nanomedicine. 2007;2(2):227-233.

2. Lin W, Huang YW, Zhou XD, Ma Y. In vitro toxicity of silica nanoparticles in human lung cancer cells. Toxicol Appl Pharmacol. 2006;217(3): 252-259.

3. Nishimori H, Kondoh M, Isoda K, Tsunoda S, Tsutsumi Y, Yagi K Silica nanoparticles as hepatotoxicants. Eur J Pharm Biopharm. 2009;72(3):496-501.

4. Paek HJ, Lee YJ, Chung HE, et al. Modulation of the pharmacokinetics of zinc oxide nanoparticles and their fates in vivo. Nanoscale. 2013;5(23): 11416-11427.

5. Choi S-J, Lee J, Jeong J, Choy J-H. Toxicity evaluation of inorganic nanoparticles: considerations and challenges. Mol Cell Toxicol. 2013;9(3): 205-210.

6. Nabeshi H, Yoshikawa T, Matsuyama K, et al. Systemic distribution, nuclear entry and cytotoxicity of amorphous nanosilica following topical application. Biomaterials. 2011;32(11):2713-2724.

7. Yoshida T, Yoshioka Y, Tochigi S, et al. Intranasal exposure to amorphous nanosilica particles could activate intrinsic coagulation cascade and platelets in mice. Part Fibre Toxicol. 2013;10:41.

8. Park Y-H, Bae H, Jang Y, et al. Effect of the size and surface charge of silica nanoparticles on cutaneous toxicity. Mol Cell Toxicol. 2013;9(1): $67-74$
9. Gong C, Tao G, Yang L, Liu J, He H, Zhuang Z. The role of reactive oxygen species in silicon dioxide nanoparticle-induced cytotoxicity and DNA damage in HaCaT cells. Mol Biol Rep. 2012;39(4):4915-4925.

10. Baek M, Chung HE, Yu J, et al. Pharmacokinetics, tissue distribution, and excretion of zinc oxide nanoparticles. Int J Nanomedicine. 2012;7: 3081-3097.

11. Kaewamatawong T, Shimada A, Okajima M, et al. Acute and subacute pulmonary toxicity of low dose of ultrafine colloidal silica particles in mice after intratracheal instillation. Toxicol Pathol. 2006;34(7) 958-965.

12. Sayes CM, Reed KL, Glover KP, et al. Changing the dose metric for inhalation toxicity studies: short-term study in rats with engineered aerosolized amorphous silica nanoparticles. Inhal Toxicol. 2010;22(4):348-354.

13. Xie G, Sun J, Zhong G, Shi L, Zhang D. Biodistribution and toxicity of intravenously administered silica nanoparticles in mice. Arch Toxicol. 2010;84(3):183-190.

14. Morishige T, Yoshioka Y, Inakura H, et al. Suppression of nanosilica particle-induced inflammation by surface modification of the particles. Arch Toxicol. 2012;86(8):1297-1307.

15. Fu C, Liu T, Li L, Liu H, Chen D, Tang F. The absorption, distribution, excretion and toxicity of mesoporous silica nanoparticles in mice following different exposure routes. Biomaterials. 2013;34(10): 2565-2575.

16. Organisation for Economic Cooperation and Development. Test No. 408: repeated dose 90-day oral toxicity study in rodents. Paris, France: Organisation for Economic Cooperation and Development Available from: http://www.oecd-ilibrary.org/environment/test-no-408repeated-dose-90-day-oral-toxicity-study-in-rodents_9789264070707en;jsessionid=2ot73f3b9t4cf.x-oecd-live-01. Accessed June 12, 2014.

17. Kim K-M, Kim H-M, Choi M-H, et al. Colloidal properties of surface coated colloidal silica nanoparticles in aqueous and physiological solution. Sci Adv Mater. 2014;6(7):1573-1581.

18. Organisation for Economic Cooperation and Development. Test No. 423: acute oral toxicity - acute toxic class method. Paris, France: Organisation for Economic Cooperation and Development. Available from: http:/www.oecd-ilibrary.org/environment/test-no423-acute-oral-toxicity-acute-toxic-class-method_9789264071001en; jsessionid=2ot73f3b9t4cf.x-oecd-live-01. Accessed June 12, 2014.

19. Paek HJ, Chung HE, Lee JA, et al. Quantitative determination of silica nanoparticles in biological matrices and their pharmacokinetics and toxicokinetics in rats. Adv Sci Mater. 2014;6(7):1605-1610.

20. Chang JS, Chang KL, Hwang DF, Kong ZL. In vitro cytotoxicitiy of silica nanoparticles at high concentrations strongly depends on the metabolic activity type of the cell line. Environ Sci Technol. 2007;41(6):2064-2068.

21. Barnes CA, Elsaesser A, Arkusz J, et al. Reproducible comet assay of amorphous silica nanoparticles detects no genotoxicity. Nano Lett. 2008;8(9):3069-3074.

22. Guo M, Xu X, Yan X, Wang S, Gao S, Zhu S. In vivo biodistribution and synergistic toxicity of silica nanoparticles and cadmium chloride in mice. J Hazard Mater. 2013;260:780-788.

23. Lee S, Kim MS, Lee D, et al. The comparative immunotoxicity of mesoporous silica nanoparticles and colloidal silica nanoparticles in mice. Int J Nanomedicine. 2013;8:147-158.

24. Coccini T, Roda E, Barni S, Signorini C, Manzo L. Long-lasting oxidative pulmonary insult in rat after intratracheal instillation of silica nanoparticles doped with cadmium. Toxicology. 2012;302(2-3): 203-211.

25. Ivanov S, Zhuravsky S, Yukina G, Tomson V, Korolev D, Galagudza M. In vivo toxicity of intravenously administered silica and silicon nanoparticles. Materials. 2012;5(10):1873-1889. 


\section{Publish your work in this journal}

The International Journal of Nanomedicine is an international, peerreviewed journal focusing on the application of nanotechnology in diagnostics, therapeutics, and drug delivery systems throughout the biomedical field. This journal is indexed on PubMed Central,

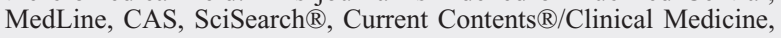

Journal Citation Reports/Science Edition, EMBase, Scopus and the Elsevier Bibliographic databases. The manuscript management system is completely online and includes a very quick and fair peer-review system, which is all easy to use. Visit http://www.dovepress.com/ testimonials.php to read real quotes from published authors.

Submit your manuscript here: http://www.dovepress.com/international-journal-of-nanomedicine-journal 